\title{
Mapping of the Bedrock Topography Using Gravity Data: A Case Study in the South of Hormozgan Province, Iran
}

Payam Salimi* and Asghar Teymorian Motlagh

Department of Geophysics, Islamic Azad University, Hamedan Branch, Iran

\begin{abstract}
Modeling of gravity data is used extensively to illustrate the geometry and interface between the sediments and bedrock. There are various methods to illustrate the bedrock topography, and we will describe one of these methods in present paper. Using the upward continuation, we extract the residual gravity anomaly which in fact shows the local effect of bedrock gravity on the observed gravity. Then, according to the following method, the residual gravity data are inversed.

The topography of a slab with infinite horizontal size which is considered with flat bottom and wavy top and by a uniform density contrast with respect to upper layers has been inversed while all calculations are carried out in Fourier domain. It should be noted that some softwares like Surfer and Excel are used in this research but the program main code is written using Matlab programming. Using the data from gravimetry performed in south of Hormozgan province, this method has been utilized to determine the bedrock topography and the results were in accordance with the local geology.
\end{abstract}

Keywords: Modeling; Bedrock topography; Upward continuation; Residual anomaly; Inversion; Fourier domain

\section{Introduction}

Estimating the bedrock depth is one of the main aims of geophysics that is used in engineering and explorations, extensively. For example, in damming it is used to design the dam foundation and construction. Determination of the bedrock depth and as a result determination of the sedimentary zones plays a vital role in estimating the earthquake danger because by trapping the surface waves, the sedimentary zones could increase the magnitude and duration of an earthquake. Today, determination of the bedrock geometry and along that determination of the boundary of layers with density contrast in various depths, are among the main aims in many construction and fundamental projects including underground water exploration, massive structures construction, underground tunnels to transmit water, underground trains and/or the place of suspended bridges legs, hence the geologists are seeking to plan proper, economic and easily executable strategies for such purposes. Since there is always a density contrast between bedrock and the upper layers, the gravimetry method used to examine these gravity changes could be significantly helpful to determine the bedrock geometry. The gravimetry includes measuring and studying the earth gravity field. These studies play a significant role in geologic sciences and constitute a base for geodesy studies that without their exact mappings a correct image of the earth situation could not be obtained.

In exploration geophysics, study and investigation of the gravity anomaly (Bouguer) have been used for oil exploration and mining for a long time, but it has been less implemented in water investigations, geotechnics and engineering. The gravity studies in exploration are based on local heterogeneity of minerals and rocks density. In a study of local gravity field, except for density variations, other factors such as topography, altitude, geographical location, etc. also affect the gravity field, which in most cases their related values are higher than the values related to the density variations. Therefore, before interpretation, the raw data must be corrected for the factors mentioned above. The resulted gravity field (after corrections), associated with density variations, is called Bouguer anomaly.
In petroleum exploration studies, due to the high volume of salt domes, the gravity anomalies up to tens of $\mathrm{mGals}$ can be expected, while for the low volume of mineral veins and masses, these anomalies are just few tenths mGals or less and they could seldom reach to a few mGals. Today, gravity field measuring devices, called Gravimeter, could measure the relative amounts of gravity with a precision of hundredth $\mathrm{mGal}$; even precisions of nano-Gals (micro-gravimeters) for engineering and water studies can be measured.

Several authors have presented different algorithms to compute the geometry of a density interface related to a known gravity anomaly. Some of them (e.g. Cordell and Henderson [1]; Dyrelius and Vogel [2]; Rao and babu [3], among others) use an approximation to the perturbing body by means of several rectangular prisms of constant density. The gravity effect for each prism is calculated and then, the total gravitational field is determined by adding the effect of all prisms. Tsuboi [4] gave a simple but efficient method based on equivalent stratum technique to compute $3 \mathrm{D}$ topography of a density interface. Another algorithm (e.g. Oldenburg [5]) is based on the rearrangement of the forward algorithm by Parker [6]. The Parker's scheme is based on the Fourier transform of the gravitational anomaly as a result of the sum of the Fourier transforms of the powers of the surface causing the anomaly. Oldenburg [5] demonstrated that Parker's expression could be rearranged in order to determine the geometry of the density interface from the gravity anomaly.

*Corresponding author: Payam Salimi, Department of Geophysics, Islamic Azad University, Hamedan Branch, Iran, E-mail: p_salimi_903@yahoo.com

Received July 14, 2012; Accepted November 17, 2012; Published November 28, 2012

Citation: Salimi P, Motlagh AT (2012) Mapping of the Bedrock Topography Using Gravity Data: A Case Study in the South of Hormozgan Province, Iran. J Geophys Remote Sensing 1:105. doi:10.4172/2169-0049.1000105

Copyright: ( 2012 Salimi P, et al. This is an open-access article distributed under the terms of the Creative Commons Attribution License, which permits unrestricted use, distribution, and reproduction in any medium, provided the original author and source are credited. 
Citation: Salimi P, Motlagh AT (2012) Mapping of the Bedrock Topography Using Gravity Data: A Case Study in the South of Hormozgan Province, Iran. J Geophys Remote Sensing 1:105. doi:10.4172/2169-0049.1000105

Page 2 of 6

\section{Method Theory}

\section{The upward continuation method to extract residual gravity from regional gravity}

For decades, separating regional and residual fields has been a vital subject in gravimetry and magnetism. A proven process for separating regional and residual fields is through convolution with what is called "separation filter". The term "residual" is used for the modeling field with shallow to intermediate scattering source and the term "regional" is implemented for the field with a deeper area [7]. In other words, the observed field $\mathrm{f}_{0}$ is the summation of the regional field $\mathrm{f}_{\text {reg }}$, residual $\mathrm{f}_{\text {res}}$, and noise $\mathrm{f}_{\text {noise }}$ fields:

$$
f_{0}(r)=f_{\text {reg }}(r)+f_{\text {res }}(r)+f_{\text {noise }}(r)
$$

Suppose that the source of anomaly in our case, forms half of the underground space from $\mathrm{z}=0$ to $\mathrm{z} \rightarrow \infty$. Consider the residual field originating from the upper levels of $z_{0}$ and the regional field originating from lower levels of $z_{0}$. After a series of mathematical relationships we will have:

$$
\mathrm{P}_{\mathrm{res}}(k)=S_{0}(k)\left[1-\exp \left(-2 k z_{0}\right)\right]
$$

Where $\mathrm{S}_{0}(\mathrm{k})$ is Bouguer anomaly, $\mathrm{k}$ is the wave number and $\mathrm{z}_{0}$ is the upward distance in upward continuation.

\section{The bedrock topography Inversion, supposing a uniform density difference}

The inversion procedure uses the equation described by Parker [6] to calculate the gravity anomaly caused by an uneven, uniform layer of material by means of a series of Fourier transforms. This expression, in its one-dimensional form, is defined as:

$$
F[\Delta g(x)]=-2 \pi G \rho e^{-|k| z_{0}} \sum_{n=1}^{\infty} \frac{|k|^{n-1}}{n !} F\left[h^{n}(x)\right]
$$

where $F(\Delta g)$ is the Fourier transform of the gravity anomaly, $G$ is the gravitational constant, $\rho$ is the density contrast across the interface, $\mathrm{k}$ is the wave number, $\mathrm{h}(\mathrm{x})$ is the depth to the interface (positive downwards) and $\mathrm{z}_{0}$ is the mean depth of the horizontal interface. Oldenburg [5] rearranged this equation to compute the depth to the undulating interface from the gravity anomaly profile by means of an iterative process and is given by:

$$
F[h(x)]=-\frac{F[\Delta g(x)] e^{|k| z_{0}}}{2 \pi G \rho}-\sum_{n=2}^{\infty} \frac{|k|^{n-1}}{n !} F\left[h^{n}(x)\right]
$$

This expression allows us to determine the topography of the interface density by means of an iterative inversion procedure. In this procedure we assume the mean depth of the interface, $z_{0}$, and the density contrast associated with two media, $\rho$. The gravity anomaly is first demeaned prior to the calculation of the Fourier transform. Then, the first term of equation 4 is computed by assigning $h(x)=0$ [5] and its inverse Fourier transform provides the first approximation of the topography interface, $\mathrm{h}(\mathrm{x})$. This value of $\mathrm{h}(\mathrm{x})$ is then used in equation 4 to evaluate a new estimate of $\mathrm{h}(\mathrm{x})$. This process is continued until a reasonable solution is achieved.

Following Oldenburg [5], the process is convergent if the depth to the interface is greater than zero and it does not intercept the topography. Further, the amplitude of the interface relief should be less than the mean depth of the interface.
As the inversion operation (equation 5) is unstable at high frequencies, a high-cut filter, $\operatorname{HCF}(\mathrm{k})$ is included in the inversion procedure to ensure convergence of series. This filter is defined by:

$$
\begin{aligned}
& H C F(k)=\frac{1}{2}\left[1+\cos \left(\frac{k-2 \pi W H}{2(S H-W H)}\right)\right] \text { for } W H<k<S H \\
& H C F(k)=0 \text { for } S H<k \\
& H C F(k)=1 \text { for } W H>k
\end{aligned}
$$

is used to restrict the high frequency contents in the Fourier spectrum of the observed gravity anomaly. The frequency, $\mathrm{k}$ can be expressed as $1 / \lambda ; \lambda$ being the wavelength in kilometers. The iterative process is terminated when a certain number of iterations has been accomplished or when the difference between two successive approximations to the topography is lower than a pre-assigned value as the convergence criteria.

Once the topographic relief is computed from the inversion procedure, it is desirable to compute the gravity anomaly produced by this computed topography [8]. In general, this modeled anomaly must be very similar to the one used as input at the first step of the inversion process.

\section{Geological and geographical information about the studied field}

The region is located in the southern province of Hormozgan, Iran of longitudes between $\left(53^{\circ}, 54^{\prime}\right)$ to $\left(54^{\circ}, 24^{\prime}\right)$ to east and latitudes between $\left(26^{\circ}, 43^{\prime}\right)$ to $\left(26^{\circ}, 56^{\prime}\right)$ to north. Regarding the divisions in geology of Iran, the area under study is located in Zagros chain that covers the northern zone of Bandar Abbas to the west of Bandar Lengeh [9]. The regions located in this area are part of the southwest region of the Zagros Mountains that include two sub-zones of high Zagros and folded Zagros (Figure 1). The main difference between these two sub-zones, in the part related to Hormozgan province, is mainly that of structural differences, but not much difference from rock sequences. In a tectonic point of view, the area structures are mostly a sequence of parallel anticlines/synclines which have more or less an east-west trend [10] (Figure 2).

\section{The real gravity data from the studied region}

Real data in the south of Hormozgan province are obtained by CG3 gravity meter SCINTREX (Automated Gravity Meter) along the 19 profiles that have an approximate direction of north-south. The region has dimensions of about $23 \mathrm{~km}$ north-south and $50 \mathrm{~km}$ east-west. Then, the raw data are processed and the various corrections are applied to obtain Bouguer anomaly [11] (Figures 3 and 4).

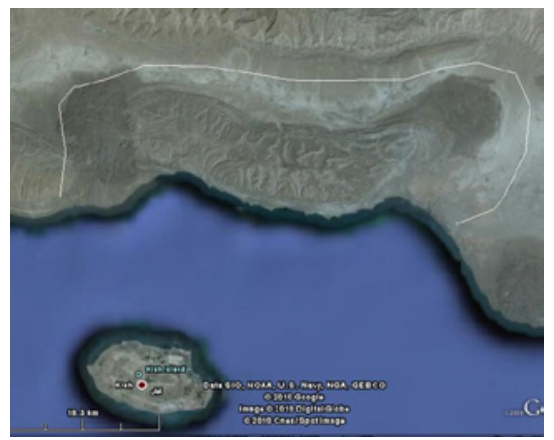

Figure 1: Aerial map of the studied area in south of Hormozgan province. 
Citation: Salimi P, Motlagh AT (2012) Mapping of the Bedrock Topography Using Gravity Data: A Case Study in the South of Hormozgan Province, Iran. J Geophys Remote Sensing 1:105. doi:10.4172/2169-0049.1000105

Page 3 of 6

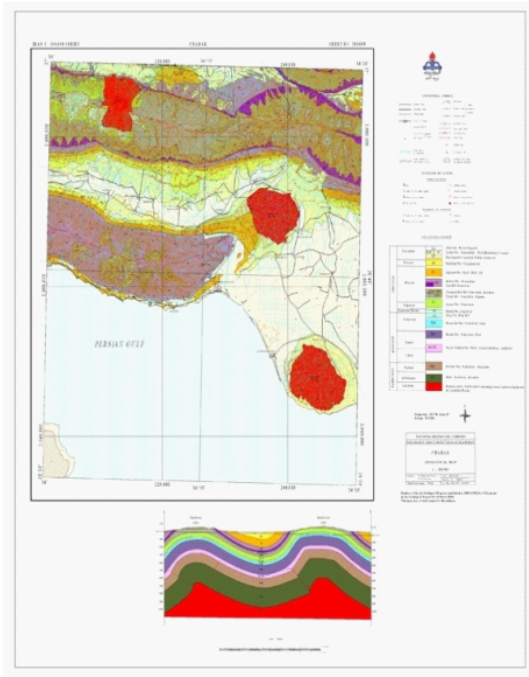

Figure 2: Geological map of the studied area.

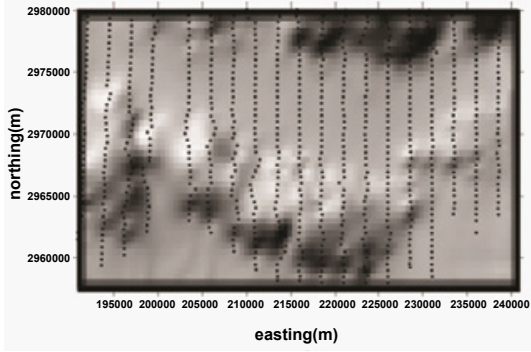

Figure 3: Topography map of gravity measurement points and profiles locations (each point represents a station).

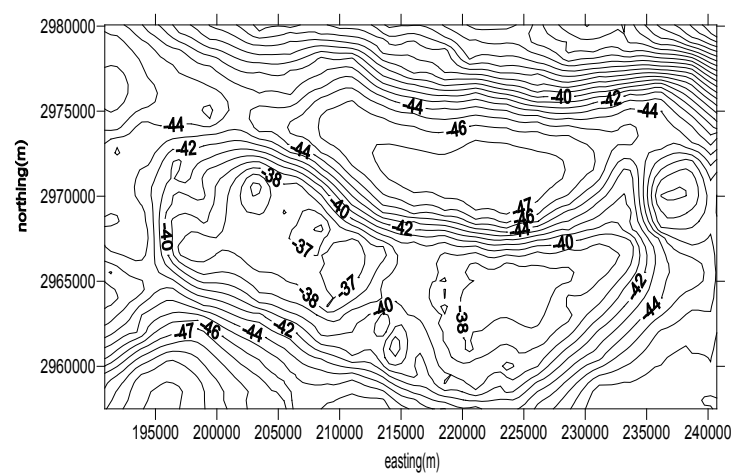

Figure 4: Contouring map of the Bouguer anomaly (the distance between contour lines is $1 \mathrm{mGal}$ ).

\section{Applying the upward continuation to separate the local field from regional field}

The upward continuation method transfers measured data from the measuring level to a higher level. This data transfer to higher level (levels) is performed by mathematical tools and numerical calculations [12]. This transfer weakens the anomalies with shorter wavelength. These anomalies are related to surface effects and/or the noise existed in gravity anomaly maps. So with this transfer, the anomalies related to shallow surfaces will be weakened or vanished, and the anomalies related to wider and deeper sources appear clearly. Regional and residual anomalies integration is in fact a mixture of effects of two resources which one is located under the other. And if these anomalies are not completely separated from each other, the regional anomaly that is the purpose of exploration can't show itself as a closed contour and the desired anomaly is poorly understood. If more upward continuation is required, the desired anomalies would be removed and if less upward continuation is required, anomalies can't be accurately detected. After necessary corrections, first we get Bouguer anomaly [13]. Then, using the upward continuation the residual anomaly which indicates the local field is extracted from Bouguer anomaly. According the equation 2,

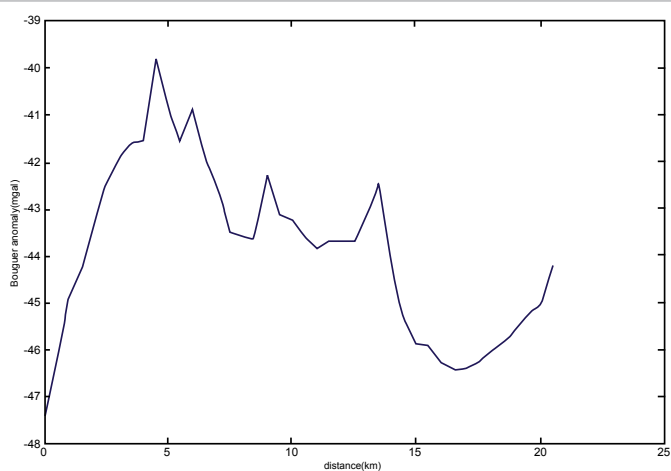

Figure 5: Complete Bouguer anomaly of a profile of the region.

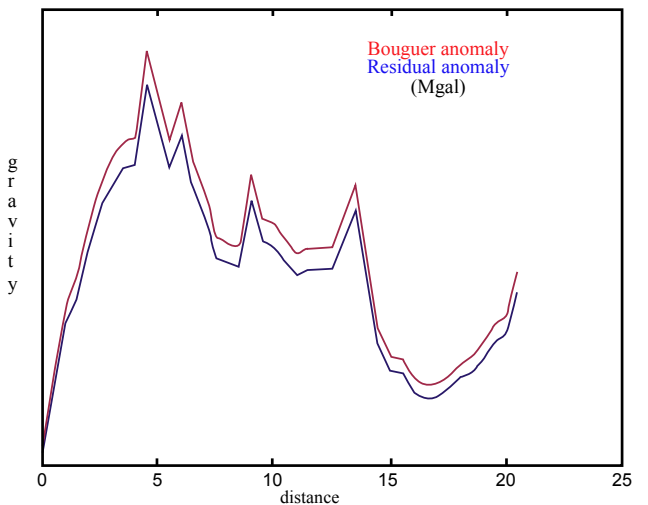

Figure 6: Comparing the profile Bouguer anomaly with residual anomaly of the same profile for the 250 meter continuation distance.

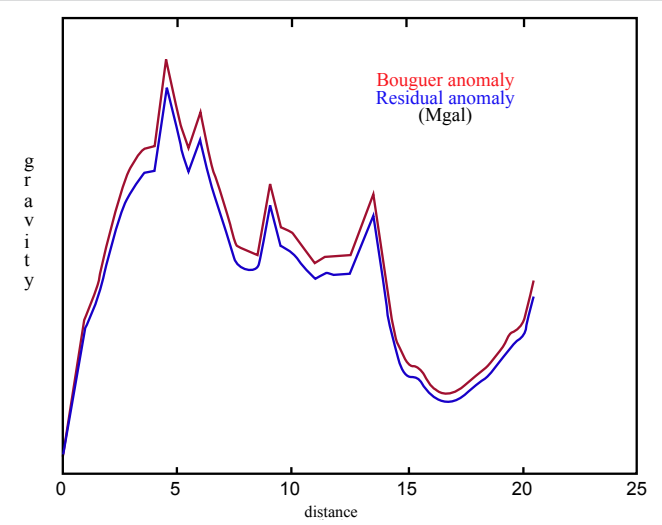

Figure 7: Comparing the profile Bouguer anomaly with residual anomaly of the same profile for the 500 meter continuation distance. 


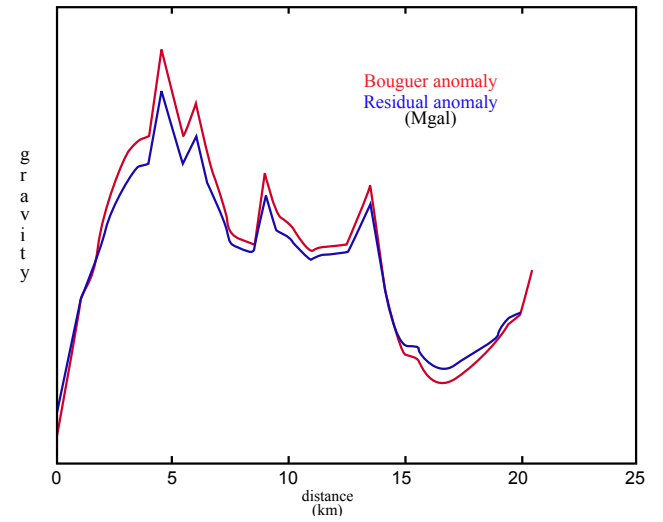

Figure 8: Comparing the profile Bouguer anomaly with residual anomaly of the same profile for the 3000 meter continuation distance.

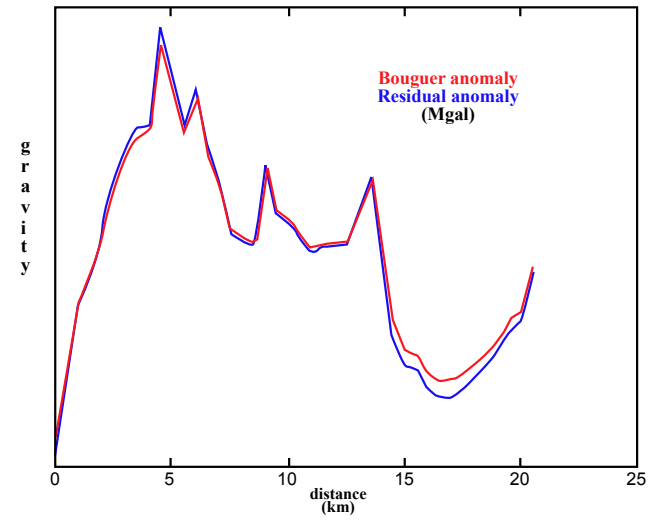

Figure 9: Comparing the profile Bouguer anomaly with residual anomaly of the same profile for the 5000 meter continuation distance.

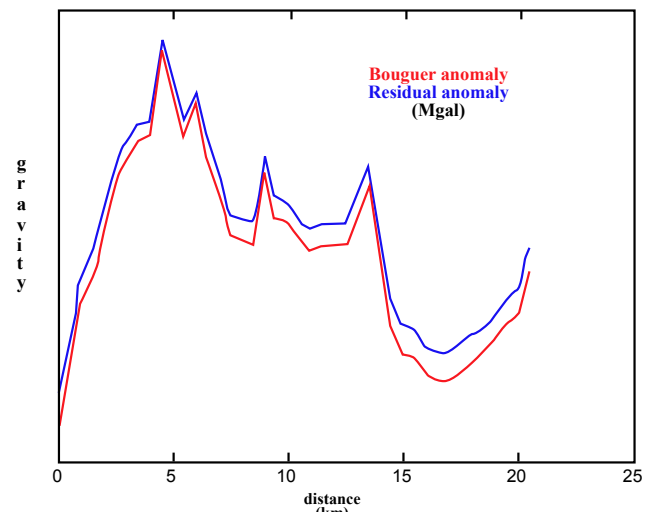

Figure 10: Comparing the profile Bouguer anomaly with residual anomaly of the same profile for the 7000 meter continuation distance.

the most important factor in upward continuation is the distance of travel, meaning that what distance should be used such that the residual anomaly could completely show the bedrock topography. It needs to select a profile from the region. Then, the various continuation distances should be applied on that profile and then the two-dimensional shape of each of the residual anomalies should be compared with Bouguer anomaly of that profile. Each continuation distance which makes more similarities with Bouguer anomaly, is in fact our desired continuation distance and the residual anomalies for whole points should be

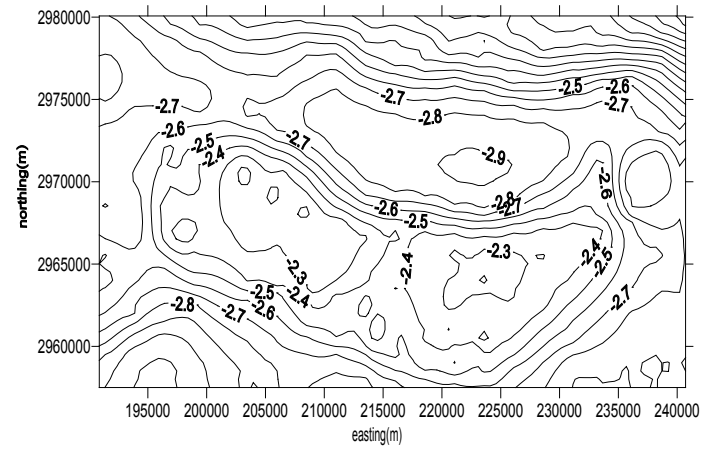

Figure 11: Contouring map of the residual anomaly (the distance between contour lines $0.1 \mathrm{mGal}$ ).

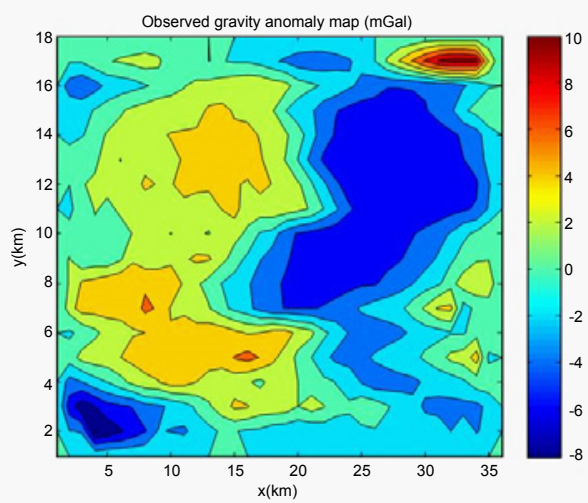

Figure 12: The observed gravity anomaly map (mGal).

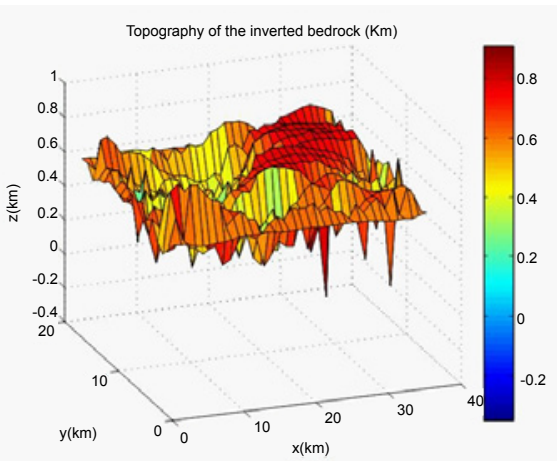

Figure 13: 3D illustration of bedrock topography $(\mathrm{km})$.

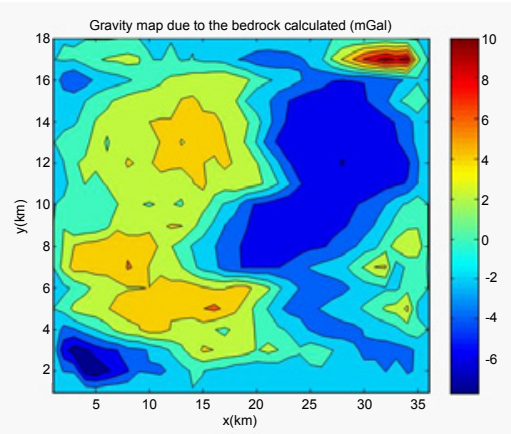

Figure 14: The gravity map calculated from the topography of bedrock (mGal). 
Citation: Salimi P, Motlagh AT (2012) Mapping of the Bedrock Topography Using Gravity Data: A Case Study in the South of Hormozgan Province, Iran. J Geophys Remote Sensing 1:105. doi:10.4172/2169-0049.1000105

Page 5 of 6

\begin{tabular}{|c|c|c|c|c|c|c|c|c|}
\hline \multicolumn{9}{|c|}{ Sampling Geophysical Properties Log (Fars) } \\
\hline \multirow[t]{2}{*}{ Sampling No. } & \multirow[t]{2}{*}{$S$ tratum } & \multicolumn{2}{|c|}{ Properties } & \multicolumn{2}{|c|}{ Coordinate } & \multirow[b]{2}{*}{ Northing } & \multirow[b]{2}{*}{ Easting } & \multirow[t]{2}{*}{ Remarks } \\
\hline & & Density & Susceptability & Long. & Lat. & & & \\
\hline 001 & Bk & 1.87 & $5.4-6.2$ & $54^{\circ} 36^{\prime} 48.2^{\prime \prime}$ & $26^{\circ} 31^{\prime} 48.6^{\prime \prime}$ & 2936611.72 & 262194.19 & \multirow{26}{*}{$\begin{array}{l}\text { Density (g/cc) } \\
\text { Susceptability (S I) }\end{array}$} \\
\hline 002 & & 1.90 & $7.0-8.0$ & & & & & \\
\hline 003 & & 1.90 & $5.5-8.0$ & & & & & \\
\hline 004 & & 1.89 & $6.0-6.1$ & & & & & \\
\hline 005 & & 1.86 & $5.0-5.5$ & & & & & \\
\hline 001 & $\mathrm{Mn}$ & 2.14 & $1.6-2.5$ & $54^{\circ} 17^{\prime} 13.1^{\prime \prime}$ & $24^{\circ} 47^{\prime} 46.0^{\prime \prime}$ & 2966733.21 & 230282.44 & \\
\hline 002 & & 2.12 & $1.6-2.0$ & & & & & \\
\hline 003 & & 2.13 & $1.5-2.1$ & & & & & \\
\hline 004 & & 2.07 & $1.9-2.2$ & & & & & \\
\hline 005 & & 2.14 & $1.6-1.8$ & & & & & \\
\hline 001 & $\mathrm{Aj}$ & 2.03 & 221-222 & $54^{\circ} 16^{\prime} 57.4^{\prime \prime}$ & $26^{\circ} 48^{\prime} 05.9^{\prime \prime}$ & 2967233.19 & 229861.79 & \\
\hline 002 & & 2.02 & 194-223 & & & & & \\
\hline 003 & & 2.04 & $198-205$ & & & & & \\
\hline 001 & Bgp & 2.45 & $1.6-2.0$ & $53^{\circ} 38^{\prime} 17.8^{\prime \prime}$ & $27^{\circ} 05^{\prime} 02.0^{\prime \prime}$ & 3000183.24 & 166601.19 & \\
\hline 002 & & 2.39 & $0.8-1.0$ & & & & & \\
\hline 003 & & 2.41 & $0.6-1.0$ & & & & & \\
\hline 004 & & 2.45 & $0.6-0.8$ & & & & & \\
\hline 005 & & 2.39 & $0.6-0.8$ & & & & & \\
\hline 006 & & 2.44 & $3.5-4.0$ & $53^{\circ} 38^{\prime} 18.6^{\prime \prime}$ & $27^{\circ} 04^{\prime} 57.3^{\prime \prime}$ & 3000037.9 & 166619.37 & \\
\hline 007 & & 2.43 & 3.3-4.0 & & & & & \\
\hline 008 & & 2.43 & $3.4-4.2$ & & & & & \\
\hline 009 & & 2.45 & $3.0-4.2$ & & & & & \\
\hline 010 & & 2.44 & $2.7-4.0$ & & & & & \\
\hline 001 & Gurpi & 2.36 & $1.4-1.8$ & $53^{\circ} 37^{\prime} 43.3^{\prime \prime}$ & $27^{\circ} 04^{\prime} 18.3^{\prime \prime}$ & 2998862.83 & 165614.02 & \\
\hline 002 & & 2.32 & $1.5-2.0$ & & & & & \\
\hline 003 & & 2.32 & $0.8-1.2$ & & & & & \\
\hline
\end{tabular}

Table 1: The density of some samples from the field under study (in terms of $\mathrm{gr} / \mathrm{cm}^{3}$ ).

calculated using this. As we shall see, the two-dimensional form of residual gravity for a selected profile with 42 stations with the distances 250, 500, 3000, 5000 and 7000 meters are drawn and compared with the two-dimensional form of the Bouguer anomaly of the same profile. As can be seen in illustrations, the 2-D figures of upward continuation of 5000 meters are more similar to the Bouguer anomaly of the profile. Therefore, to determine the residual anomaly of all points, the upward continuation of 5000 meters is used [14] (Figures 5-11).

\section{Sediment sampling to determine the desired region density}

Density in the desired region was determined using field sampling and measurement of the samples densities in laboratory. This density determination plays a crucial role in estimating the difference in density between the bedrock and the upper sediments. In the following table, we see some of these samplings (Table 1).

\section{Three-dimensional topography inversion}

The first parameter we need is the density difference between bedrock and the upper sediments. According to geological mapping and drillings existed in the area, bedrock density is estimated to be 3.2 $\mathrm{gr} / \mathrm{cm}^{3}$, and the upper sediments density is estimated to be $2.4 \mathrm{gr} / \mathrm{cm}^{3}$ [15-18]. Thus, the density difference put into calculations is considered to be $0.8 \mathrm{gr} / \mathrm{cm}^{3}$. Also, the basic surface around which the topography is calculated extends to the top of the bedrock and is 600 meters (considering the geology maps and drillings), such that all the bedrock is located under it [19]. Convergence is obtained in second iteration in iterative method which is obtained by the standard deviation ( $\mathrm{rms}$ error) of about $0.0146 \mathrm{~km}$ (convergence criterion in $0.02 \mathrm{~km}$ ). The maximum depth is obtained around $950 \mathrm{~m}$ under reference surface and the maximum height around $310 \mathrm{~m}$ above reference surface [20-23] (Figures 12-14).

\section{Conclusion}

Fast Fourier transforms is the basis of this study which is very useful for reducing computational time. For program convergence it is vital to change the filter parameters which are related to bedrock geometry. If the topography to be simulated is located in more depths, a filter that uses longer wavelengths should be designed. Choice of filter parameters and also the bedrock depth should vary from one location to another. Therefore, selection of the depth of reference surface depends on the specifications of the region under study and additional data like geophysical and geological data. Basically, these approaches that make use of fast Fourier transforms are the best methods of calculation. Such that these methods are easily implemented in various methods of geophysical interpretations which require a lot of processing. In a broad range of different densities and different depths, joint studies with other geophysical explorations including seismic profiles to obtain a subsurface structure (eg, bedrock topography) are very useful and important.

\section{References}

1. Cordell L, Henderson RG (1968) Iterative three-dimensional solution of gravity anomaly data using a digital computer. Geophysics 38: 596-601.

2. Dyrelius D, Vogel S (1972) Improvement of convergency in iterative gravity interpretation. Geophys J R Astr Sot 27: 195-205.

3. Rao D, babu N (1991) A rapid method for three-dimensional modeling of magnetic anomalie. Geo physics 56: 1729-1737.

4. Tsuboi C (1983) Gravity, first ed. George Allen \& Unwin Ltd London, pp.254 
Citation: Salimi P, Motlagh AT (2012) Mapping of the Bedrock Topography Using Gravity Data: A Case Study in the South of Hormozgan Province, Iran. J Geophys Remote Sensing 1:105. doi:10.4172/2169-0049.1000105

5. Oldenburg D (1974) The inversion and interpretation of gravity anomalies. Geophysics 39: 526-536.

6. Parker RL (1973) The rapid calculation of potential anomalies. Geophys J R Astron Soc 31: 447-455.

7. Berman H, Daly RA, Spicer HC (1942) Density at room temperature and 1 atmosphere. In: Birch F (1942) Handbook of Physical Constants. Geological Society of America, USA.

8. Bott MHP (1960) The use of rapid digital computing methods for direct gravity interpretation of sedimentary basins. Geophys J R Astr Soc 3: 63-67.

9. Bullard EC, Cooper RIB (1948) The determination of the masses necessary to produce a given gravitational field. Proc R Soc Lond A 194: 332-347.

10. Boulanger O, Chouteau M (2001) Constraints in 3D gravity inversion. Geophysical Prospecting 492: 265-280.

11. Clarke C (1969) Optimum second-derivative and downward-continuation filters. Geophysics. 34: 424-437.

12. Corbato CG (1965) A least-squares procedure for gravity interpretation. Geophysics 30: 228-233.

13. Grant FS, West GF, (1965) Interpretation theory in applied geophysics. McGraw-Hill, USA.
14. Bingham C (1967) Fast Fourier transform and its application to digital filtering and spectral analysis. AU-IS.

15. Jacobsen B (1987) A case for upward continuation as a standard separation filter for potential field maps. Geophysics 52: 1138-1148.

16. Jakosky JJ (1950) Exploration Geophysics. (2ndedn), Trija Publishing, USA.

17. Last BJ, Kubik K (1983) Compact gravity inversion. Geophysics 48: 713-721.

18. Naidu $P$ (1966) Extraction of potential field signal from a back ground of randomnoise by Strakhov's methods. J Geophys Res 71: 5987-5995.

19. Negi G, Garde C (1969) Symmetric matrix method for gravity interpretation Geophys 74: 3804-3807.

20. Parasnis DS (1997) Principles of Applied Geophysics. (4thedn), Chapman \& Hall, UK.

21. Tanner JG (1967) An automated method of gravity interpretation. Geophys 13 339-347.

22. Whittaker ET, Watson GN (1962) A course of modern analysis. Cambridge University Press, UK.

23. Worzel I (1965) Pendulum gravity measurements at sea 1936-1959. New York, John Wiley and Sons. 